\title{
Masked Hypertension in Adolescents with Type 1 Diabetes Mellitus: An Exploratory Study
}

\author{
Bachar Afandi ${ }^{a, b}$ Bassam Bernieh $^{a}$ Sana Roubi $^{a} \quad J u m a A l$ Kaabi ${ }^{a, b}$ \\ aDepartment of Internal Medicine, College of Medicine and Health Sciences, United Arab Emirates \\ University, Al-Ain, United Arab Emirates; ${ }^{\text {TT} T a w a m ~ D i a b e t e s ~ a n d ~ E n d o c r i n e ~ C e n t e r, ~ T a w a m ~ H o s p i t a l, ~}$ \\ Al-Ain, United Arab Emirates
}

\section{Keywords}

Hypertension · Masked hypertension · Blood pressure measurement · Type 1 diabetes mellitus

\begin{abstract}
Introduction: Masked hypertension (MHTN) is the finding of elevated out-of-office blood pressure (BP) measurement. This is a pilot study to evaluate the prevalence of MHTN in adolescents with type 1 diabetes mellitus (T1DM). Patients and Methods: Normotensive, adolescents with T1DM were recruited from Tawam Adolescents Diabetes Clinic at Tawam hospital, Al Ain, UAE. They consented to wear the ambulatory BP monitoring (ABPM) device. The heart rate and ambulatory BP were recorded at 15-min intervals for $24 \mathrm{~h}$. Abnormal systolic BP (SBP) and diastolic BP (DBP) were defined as readings above 135 and $85 \mathrm{~mm} \mathrm{Hg}$; respectively. Results: Thirteen patients ( 10 females) were recruited from "Tawam Adolescents Diabetes Clinic." The median age was 17 (15-19) years, median BMI 21.4 (14.8-29), and median diabetes duration 9 (3-12) years. All patients had normal retinal examination within the past 12 months. Family history of hypertension (HTN) was present in 6/13 (46\%) patients. Office BP measurements revealed a mean DBP \pm SD of $72 \pm 6.9 \mathrm{~mm} \mathrm{Hg}$ and mean SBP \pm SD $116 \pm 5.5 \mathrm{~mm} \mathrm{Hg}$. The
\end{abstract}

median HbA1c was 8.4\% (5.6-13.7) and median GFR 125 $\mathrm{mL} / \mathrm{min} / \mathrm{m}^{2}$ (87-134). Two patients had microalbuminuria. Twenty-four hour ABPM revealed elevated SBP and DBP in 12.2 and $5.8 \%$ of the values; respectively. Further analysis confirmed MHTN in 4 (30\%) patients, nondipping pattern of $\mathrm{BP}$ in $5(38 \%)$ patients, and elevated pulse pressure in 8 (61.5\%) patients. Only 4 (30\%) patients had normal studies. Conclusions: ABPM uncovered a very high prevalence of MHTN in our patients. Whenever available, ABPM provides an excellent tool for diagnosis and hence early evaluation and management of HTN in adolescents with T1DM. Welldesigned large-scale studies are needed to examine the magnitude of MHTN among adolescents with T1DM.

\footnotetext{
(C) 2021 The Author(s)

Published by S. Karger AG, Basel
}

\section{Introduction}

Conventional blood pressure (BP) categorization is based on the average of 2 or more properly taken $\mathrm{BP}$ measurements on 2 or more occasions in a healthcare setting. Normal BP is defined by a systolic BP (SBP) $<120 \mathrm{~mm} \mathrm{Hg}$

Bassam Bernieh deceased on 30 September 2020. karger@karger.com www.karger.com/dde

Karger $\stackrel{\text { ' }}{5}$

BOPEN ACCESS
C) 2021 The Author(s)

Published by S. Karger AG, Basel

This is an Open Access article licensed under the Creative Common Attribution-NonCommercial-4.0 International License (CC BY-NC) (http://www.karger.com/Services/OpenAccessLicense), applicable to the online version of the article only. Usage and distribution for commercial purposes requires written permission.
Correspondence to:

Bachar Afandi, bafandi@seha.ae 
and a diastolic BP (DBP) $<80 \mathrm{~mm} \mathrm{Hg}$, whereas hypertension (HTN) is defined as either an SBP $\geq 140 \mathrm{~mm} \mathrm{Hg}$ or DBP $\geq 90 \mathrm{~mm} \mathrm{Hg}$ [1].

The prevalence of masked HTN (MHTN) is estimated to range between 10 and $30 \%$ of individuals [2]. MHTN was diagnosed by ambulatory BP monitoring in $14 \%$ of individuals and by home BP monitoring in $11 \%$ of individuals [3]. Patients with MHTN are at increased target organ damage as it is an indicator for increased risk of atrial fibrillation, stroke, $\mathrm{CKD}$, coronary artery calcification, and even mortality from cardiovascular disease [4, 5]. Identification of patients with MHTN is possible using either (a) home BP monitoring or (b) 24-h ambulatory BP monitoring (ABPM) [6].

ABPM is the gold standard to estimate: the mean BP level, diurnal rhythm of BP and estimation of pulse pressure. In clinical practice, the use of ABPM is indicated in patients suspected to have: white-coat HTN, HTN in pregnancy, MHTN, nocturnal HTN, episodic HTN, nondipping at night, and poor BP control despite appropriate treatment [6]. The accepted phenotypes of HTN measured by ABPM are shown in Table 1; these BP patterns differ markedly in prevalence, clinical characteristics, burden organ damage as well as risk of cardiovascular morbidity and mortality.

The prevalence of MHTN was reported to be $9.5 \%$ in youths with type 1 diabetes mellitus (T1DM) [7]. To the best of our knowledge, there is no previous study in the UAE examining the prevalence of MHTN in adolescents with T1DM. Considering the increasing prevalence of T1DM in the MENA region, the literature review has shown scarce publications addressing this issue [8]. This is a pilot study to evaluate the prevalence of masked HTN in adolescents' patients with T1DM.

\section{Patients and Methods}

This is a cross-sectional pilot study. We aimed to evaluate the prevalence of MHTN in a sample of adolescent patients with T1DM regularly attending the outpatient Tawam Adolescents Diabetes Clinic at Tawam hospital, Al Ain, UAE. Inclusion criteria included: adolescents with T1DM for at least 3-year duration, aged 15-20 years, postpubertal, and are known to be normotensive on previous visits. Exclusion criteria were prepubertal patients, outside the specified age range, pregnancy, elevated office BP, receiving antihypertensive medications, having evidence of organ damage such as established diabetic retinopathy, abnormal renal function tests, and having overt proteinuria or hematuria. Following written informed consent, patients wore the ABPM device (MOBIL-O-GRAPH NG Version 12. I.E.M. GmbH. Stolberg, Germany) [9]. Ambulatory BP measurements were taken at 15-min in-

Masked Hypertension in UAE

Adolescents with Type 1 Diabetes Mellitus
Table 1. Phenotypes of BP measured in the office and by ABPM

\begin{tabular}{lll}
\hline & In-office BP & Out-of-office BP \\
\hline Sustained normotension & Normal & Normal \\
Sustained HTN & Elevated & Elevated \\
White coat HTN & Elevated & Normal \\
MHTN & Normal & Elevated \\
\hline
\end{tabular}

HTN, hypertension; MHTN, masked hypertension; ABPM, ambulatory BP monitoring; BP, blood pressure.

tervals throughout the subsequent 24 -h period, and the device was returned the next day.

The study was conducted during the months of October and November 2018. Sixteen patients screened, 3 excluded (1 delayed puberty, 1 true HTN, and 1 did not consent). A total of 13 Patients, 10 females and 3 males were enrolled into the study. All subjects received verbal and written information about the study and written informed consent was obtained from all the study participants.

We evaluated the rates of masked systolic HTN and masked diastolic HTN. Normotensive, adolescents with T1DM were included in this study. After determining the appropriate cuff size, the device was applied to the nondominant arm and comparing ambulatory readings with an office measurement for correlation. To minimize errors and capture adequate number of readings, instructions and education were delivered to the patients and parents by the treating physician and the nurse educator. A record was kept for the activity and sleep periods. In order to obtain a sufficient number of recordings for interpretation, we programmed the device to record the heart rate and ambulatory BP at 15-min intervals for $24 \mathrm{~h}$. The minimum acceptable ABPM readings of the study to be evaluated was $70 \%$ of the possible 1,248 readings. This can be obtained with at least 28 readings per subject during the daytime period and at least 10 readings during the nighttime period.

\section{Definitions}

SBP and DBP: SBP and DBP thresholds for daytime, $24 \mathrm{~h}$, and nighttime HTN were based on the USA and international guidelines $[6,10]$.

Clinic office HTN: It was defined as a mean clinic SBP $\geq 140$ $\mathrm{mm} \mathrm{Hg}$ or mean clinic DBP $\geq 90 \mathrm{~mm} \mathrm{Hg}$.

ABPM: Abnormal ABPM, SBP, or DBP was defined as recording readings with a mean above $135 \mathrm{~mm} \mathrm{Hg}$ systolic and 85 diastolic $\mathrm{mm} \mathrm{Hg}$ for any time period, respectively.

Masked HTN: Masked HTN was defined as having an elevated mean BP for any ABPM time (day or night) period [9].

Abnormal nighttime dipping: Abnormal nighttime dipping was defined as the absence of $10 \%$ lower BP readings during nighttime.

Reverse/or inverted dipping: Reverse/or inverted dipping was defined as a higher nighttime mean BP compared with daytime BP values.

Abnormal pulse pressure: Abnormal pulse pressure was identified when the difference between SBP and DBPs exceeded $55 \mathrm{~mm}$ Hg [10-12]. 


\section{Results}

Thirteen subjects with T1DM (10 females) were recruited from Tawam Adolescents Diabetes Clinic. The median age was 17 (15-19), median BMI 21.4 (14.8-29), and median diabetes duration 9 years (3-12). Four patients $(30 \%)$ treated with multiple daily insulin injections and 9 patients (70\%) with an insulin pump. Family history of HTN was present in 6/13 (46\%) patients, 1 patient was an active smoker and 1 was treated with thyroxine treatment for primary hypothyroidism. All patients had a normal retinal examination within 12 months prior to the study. Office BP evaluation revealed a mean DBP \pm $\mathrm{SD} 72 \pm 6.9 \mathrm{~mm} \mathrm{Hg}$ and mean SBP $\pm \mathrm{SD} 116 \pm 5.5 \mathrm{~mm} \mathrm{Hg}$. The median HbAlc was 8.4\% (5.6-13.7) and median GFR $125 \mathrm{~mL} / \mathrm{min} / \mathrm{m}^{2}$ (87-134). Two patients (15\%) had microalbuminuria (Table 2 ).

The total reported readings of the 24-h ABPM in the study were 909 ( $72.5 \%$ of the planned readings). The $24-\mathrm{h}$ ABPM revealed elevated BP in $18 \%$ out of 909 readings recorded for all patients and elevated SBP and DBP recorded in 12.2 and $5.8 \%$, respectively. Further analysis revealed that $4 / 13(30 \%)$ patients had normal studies and confirmed MHTN in 4/13 (30\%) patients, nondipping pattern of $\mathrm{BP}$ in $5 / 13(38 \%)$ patients, and elevated pulse pressure in $8 / 13(61.5 \%)$ patients (Fig. 1).

\section{Discussion}

In the present study, all our adolescents with T1DM patients were initially classified as normotensive by conventional methods. However, the use of ABPM uncovered a very high prevalence of MHTN, nondipping pattern, and wide pulse pressure. These findings are much higher than anticipated and warrants further studies.

ABPM is superior to clinical BP monitoring in detecting and characterizing changes in $\mathrm{BP}$ throughout the observation period [13] and in predicting cardiovascular morbidity and mortality $[14,15]$. Although the optimal approach for the detection of MHTN is unknown [16, 17], screening individuals with a high risk is the best approach. MHTN has often been shown to progress to sustained HTN in older people and confers a cardiovascular risk almost similar to sustained HTN [18] in both the general population and in patients with diabetes and CKD.

Masked HTN has recently become a topic of interest in youths. ABPM revealed that one-quarter of the participants with type 1 diabetes had MHTN [19]. Children
Table 2. Baseline characteristics of participants

\begin{tabular}{lc}
\hline Characteristic & 13 patients \\
\hline Median age & 17 years $(15-19)$ \\
Median BMI & $21.4 \%(14.8-29)$ \\
Median duration of DM & 9 years $(3-12)$ \\
Median HbAlc & $8.4 \%$ and $(5.6-13.7)$ \\
Median GFR & $125 \mathrm{~mL} / \mathrm{min} / \mathrm{m}^{2}(87-134)$ \\
Smoking status & $1 / 13(7.6 \%)$ \\
Family history of HTN & $6 / 13(46 \%)$ \\
Insulin pump & $9 / 13(69 \%)$ \\
Retinal examination & $13 / 13(100 \%)$ normal \\
Proteinuria & $2 / 13(15 \%)$ \\
\hline
\end{tabular}

DM, diabetes mellitus; HTN, hypertension.

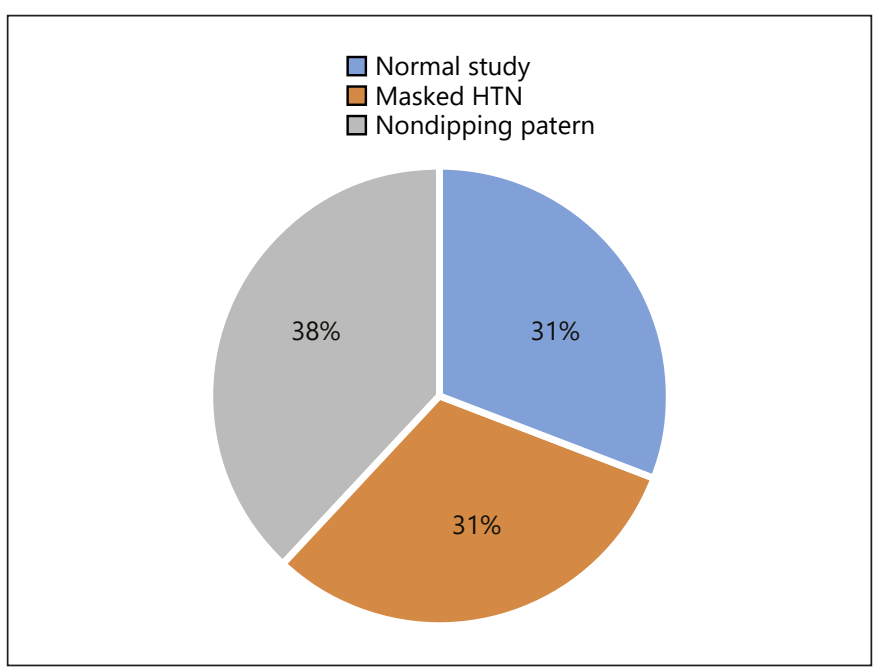

Fig. 1. Ambulatory blood pressure findings. HTN, hypertension.

with MHTN were more likely to be obese, have a positive family history for HTN, and have a higher LV mass index [20-22].

In addition to high MHTN prevalence, our patients had nondipping and/or inverted dipping pattern of BP, a phenomenon that frequently documented in HTN, type 2 diabetes mellitus, CKD, and sleep apnea syndrome. Reverse dipping is considered to be a powerful marker of adverse cardiovascular prognosis [23, 24]. Additionally, increased pulse pressure, an indicator for arterial stiffness, was reported in the majority of our small cohort. Elevated PP in children with T1DM may contribute to the high risk for early development of atherosclerosis [25].

Masked HTN in youth is an entity that is associated with increased prevalence of sustained HTN and in- 
creased risk of target organ damage. Therefore, adolescents with T1DM and MHTN should be instructed in lifestyle modifications, monitored closely, and considered for antihypertensive therapy.

The study has a few limitations, including the small sample size, lack of a control group, and lack of normative $\mathrm{BP}$ data for regional pediatric populations based on age, gender, BMI, and height. Despite all the taken precautions to obtain accurate readings, technical limitations may be present as the algorithms used in ambulatory oscillometric monitors may vary in children. Saying that, the findings of this study are alarming as possibility of previously unrecognized true hypertensives in the group is high. Considering the high prevalence of genetic predisposition for HTN, presence of overweight or obesity and uncontrolled diabetes, our data warrant future larger, well-structured studies to examine MHTN among young patients with T1DM.

\section{Conclusions}

Our cross-sectional pilot study utilizing the ABPM uncovers very high prevalence of masked HTN and cardiac risk indicators in adolescence with T1DM. Whenever available, ABPM provides an excellent tool for diagnosis and hence early evaluation and management of HTN in adolescents with T1DM. Well-designed large-scale studies are needed to examine the magnitude and determinants of MHTN among adolescents with T1DM.

\section{Statement of Ethics}

The study was approved by the Alain Institutional Research Ethics Committee (CR. D 468/16). All subjects have given their written informed consent.

\section{Conflict of Interest Statement}

The authors have no conflicts of interest to disclose.

\section{Funding Sources}

The authors did not receive any funding.

\section{Author Contributions}

All authors contributed equally to the conception of the study, data collection and analysis, drafting of the manuscript, and approval of its final version. B.B.: deceased 30 September 2020.

\section{References}

1 Whelton PK, Carey RM, Aronow WS, Casey DE Jr, Collins KJ, Dennison Himmelfarb C, et al. 2017 ACC /AHA/AAPA/ABC/ACPM/ AGS/APhA/ASH/ASPC/NMA/ PCNA Guideline for the prevention, detection, evaluation, and management of high blood pressure in adults: a report of the American College of Cardiology/American Heart Association Task Force on Clinical Practice Guidelines. Hypertension. 2018;71:e136-9.

2 O’Brien E, Parati G, Stergiou G, Asmar R, Beilin L, Bilo G, et al. European Society of hypertension position paper on ambulatory blood pressure monitoring. J Hypertens. 2013; 31(9):1731-68.

3 Stergiou GS, Asayama K, Thijs L, Kollias A, Niiranen TJ, Hozawa A, et al. Prognosis of white-coat and masked hypertension. International database of home blood pressure in relation to cardiovascular outcome. Hypertension. 2014;63:675-82.

4 Booth JN 3rd, Diaz KM, Seals SR, Sims M, Ravenell J, Muntner P, Shimbo D, et al. Masked hypertension and cardiovascular disease events in a prospective cohort of blacks: the jackson heart study. Hypertension. 2016; 68(2):501-10

Masked Hypertension in UAE

Adolescents with Type 1 Diabetes Mellitus
5 Fagard RH, Cornelissen VA. Incidence of cardiovascular events in white-coat masked and sustained hypertension versus true normotension: a meta-analysis. J Hypertens. 2007; 25:2193-8.

6 Shimbo D, Abdalla M, Falzon L, Townsend RR, Muntner P. Role of ambulatory and home blood pressure monitoring in clinical practice: a narrative review. Ann Intern Med. 2015;163(9):691-700.

7 Suláková T, Janda J, Cerná J, Janstová V, Suláková A, Slaný J, et al. Arterial HTN in children with T1DM: frequent and not easy to diagnose. Pediatr Diabetes. 2009; 10: 441-8.

8 Cakir BC, Aycan Z, Vidinlisan S, Akpinar K, Keskin SK, Cakir HT, et al. Ambulatory blood pressure monitoring for 24 hours in children with type-1 diabetes mellitus. Saudi Med J. 2007;28(11):1758-60.

9 Franssen PM, Imholz BP. Evaluation of the Mobil-O-Graph new generation ABPM device using the ESH criteria. Blood Press Monit. 2010 Aug;15(4):229-31.

10 Sherwood A, Steffen PR, Blumenthal JA, Kuhn C, Hinderliter AL. Nighttime blood pressure dipping: the role of the sympathetic nervous system. Am J Hypertens. 2002;15(2 Pt 1):111-8.

11 Cuspidi C, Sala C, Tadic M, Gherbesi E, Grassi G, Mancia G. Nondipping pattern and carotid atherosclerosis: a systematic review and meta-analysis. J Hypertens. 2016;34:385-39.

12 Garcia-Ortiz L, Gomez-Marcos MA, MartınMoreiras J, González-Elena LJ, Recio-Rodriguez JI, Castaño-Sánchez Y, et al. Pulse pressure and nocturnal fall in blood pressure are predictors of vascular, cardiac and renal target organ damage in hypertensive patients (LOD-RISK study). Blood Press Monit. 2009; 14:145-51.

13 Urbina E, Alpert B, Flynn J, Hayman L, Harshfield GA, Jacobson M, et al. American Heart Association Atherosclerosis, Hypertension, and Obesity in Youth Committee Ambulatory blood pressure monitoring in children and adolescents: recommendations for standard assessment: a scientific statement from the American Heart Association Atherosclerosis, Hypertension, and Obesity in Youth Committee of the Council on Cardiovascular Disease in the Young and the Council for High Blood Pressure Research. Hypertension. 2008;52:433-51. 
14 Metoki H, Ohkubo T, Kikuya M, Asayama K, Obara T, Hara A, et al. Prognostic significance of night-time, early morning, and daytime blood pressures on the risk of cerebrovascular and cardiovascular mortality: the Ohasama Study. J Hypertens. 2006;24(9):1841-8.

15 Banegas JR, Ruilope LM, de la Sierra A, Vinyoles E, Gorostidi M, de la Cruz JJ, et al. Relationship between clinic and ambulatory blood-pressure measurements and mortality. N Engl J Med. 2018;378(16):1509-20.

16 Anstey DE, Shimbo D. Masked hypertensionwhat lies ahead? J Hum Hypertens. 2017 Sep; 31(9):545-6.

17 Lee SH, Kim JH, Kang MJ, Lee YA, Won Yang $\mathrm{S}$, Shin $\mathrm{CH}$. Implications of nocturnal hypertension in children and adolescents with type 1 diabetes. Diabetes Care. 2011 Oct;34(10): $2180-5$.
18 Kushiro T, Kario K, Saito I, Teramukai S, Sato Y, Okuda Y, et al. Increased cardiovascular risk of treated white coat and masked hypertension in patients with diabetes and chronic kidney disease: the HONEST Study. Hypertens Res. 2017;40(1):87-95.

19 Thakkar HV, Pope A, Anpalahan M. Masked hypertension: a systematic review. Heart Lung Circ. 2020;29(1):102-11.

20 Per-Henrik Groop (FinnDiane Study Group). Ambulatory blood pressure and arterial stiffness in individuals with type 1 diabetes. Diabetologia. 2018;61:1935-45.

21 Lurbe E, Torro I, Alvarez V, Nawrot T, Paya $\mathrm{R}$, Redon J, et al. Prevalence, persistence, and clinical significance of masked hypertension in youth. Hypertension. 2005;45(4):493.

22 Luo XX, Zhu Y, Sun Y, Ge Q, Su J, So HK, et al. Does masked hypertension cause early left ventricular impairment in youth? Front Pediatr. 2018;6:167.
23 Cuspidi C, Sala C, Tadic M, Gherbesi E, De Giorgi A, Grassi G, et al. Clinical and prognostic significance of a reverse dipping pattern on ambulatory monitoring: an updated review. J Clin Hypertens. 2017 Jul;19(7):71321.

24 Lee SH, Kim JH, Kang MJ, Lee YA, Won Yang $\mathrm{S}$, Shin $\mathrm{CH}$. Implications of nocturnal hypertension in children and adolescents with Type 1 diabetes. Diabetes Care. 2011 Oct;34(10): 2180-5.

25 Dost A, Molz E, Krebs A, Bechtold S, Kapellen $\mathrm{T}$, Rohrer T, et al. Pulse pressure in children and adolescents with type 1 diabetes mellitus in Germany and Austria. Pediatr Diabetes. 2014 May;15(3):236-43. 